\title{
Luxury Retail Environments And Changing Masculine Sociocultural Norms
}

\author{
Nacima Ourahmoune, Kedge Business School, France
}

\begin{abstract}
This article explores how luxury brands communicate with male shoppers through their retail environments in the context of changing sociocultural definitions of masculinity. While Bain and Company (2012) speak of the 'masculinization of the luxury market', consumer research has paid little attention to men and masculinity (Otnes and Tuncay-Zayer, 2012). Most previous studies have tackled male representations in advertising and the tensions felt by male shoppers. This article extends this limited body of knowledge to retailing issues. It compares masculine archetypes with the discursive strategies used by retailers to target new male consumers. Using a semiotic square analysis the author reveals five masculine archetypes emphasized by luxury brands in their retail environments and discusses their implications. The findings show that most brands rely on traditional utilitarian representations of masculinity in stores, missing opportunities to renew their communication to take advantage of changing masculine values.
\end{abstract}

Keywords. Retailing; Masculinity; Luxury Stores; Semiotic Square; Communication; Gender

\section{INTRODUCTION}

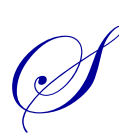

hopping is often described as a frivolous, feminine activity (Miller, 1987). Already, at the end of the nineteenth century, Emile Zola described the frenzy women displayed when the great Parisian department stores appeared in Au Bonheur des Dames. In the wake of the French Revolution, the bourgeoisie, which had become dominant in French society, separated the genders strictly: women represented beauty and domesticity whereas men represented work and the need to achieve social success (Vigarello, 2004). In the same way, the retail industry attempts to sustain women's desire to consume. Academic research has not managed to avoid associating women with consumption, and, as Otnes and Tuncay (2012) emphasize, masculine identity is still a limited area for consumer research.

Yet for marketers, masculine identity is vitally important. Bain and Company (2012) mention "a masculinization of the luxury market." The masculine segment is outperforming its feminine counterpart in many luxury product categories that used to be typically feminine, such as fashion. Since 2011 (Bain \& Company, 2012), the masculine luxury sector, representing $40 \%$ of a world market estimated at $€ 180 \mathrm{bn}$, has grown annually by $14 \%$, nearly twice the growth of the feminine luxury sector $(+8 \%)$.

Given the increasing importance of the masculine market and the little interest the literature shows in this phenomenon, our article addresses the discursive communication strategies brands use to connect with changing masculine consumers in their retail environments.

\section{Research Aim}

This research investigates the ability of the luxury retail sector to adapt to changing masculine sociocultural norms through its communication. While company reports signal major shifts in male global luxury consumption (Bain and Company 2012), masculinity has received limited attention in consumer research (Otnes and Zayer, 2012). Yet a growing body of research tackles changing masculine consumption behaviors and male representations in advertising (Belk and Costa, 1998; Holt and Thompson, 2004; Schroeder and Zwick, 2004; Rinallo 2007; Ourahmoune, 2012; Ostberg, 2012; Coskuner-Balli and Thompson, 2014). This research has not yet explored the retail environment as an important locus capturing masculine transformations. Our study therefore investigates the 
narratives luxury brands display in stores to decipher how these brands communicate with changing male consumers.

\section{Research Question}

Our research principally aims to identify the discursive logics used in the marketplace to adapt society's evolving gender representations, especially masculine identity. More specifically, I attempt to answer the following research question:

1) How do luxury brands build on specific meanings in their retail environments to communicate with changing male consumers?

To achieve this goal, I use semiotic analysis (Floch, 1995) to reveal the deep meanings contained in 15 major luxury-brand narratives in France. This research identifies five types of masculine values that brands leverage in their retail environments. I explain the meanings of each specific type of masculinity and discuss the implications of our findings.

\section{Originality of the Paper}

The paper contributes to the limited body of research investigating changing masculine identity as a complex business phenomenon, especially in the field of Consumer Culture Theory (Costa and Belk, 1998; Holt and Thompson, 2004, Schroder and Zwick, 2004, Otnes and Zayer, 2012, Coskuner-Balli and Thompson, 2014). The paper goes further in capturing the links between changing masculine sociocultural norms and branding strategies, especially in retail contexts. Retail environments are an essential point of contact between brands and consumers, offering brands an efficient communication tool (Hetzel, 2005). Yet research has mainly focused on changing masculinity in advertising (Patterson and Elliott, 2002; Schroeder and Zwick, 2004; Ourahmoune and Nyeck, 2008). I decipher how brands display masculinity in their stores. Using the semiotic square method, an original and appropriate method of deciphering meanings behind brand narratives (Floch, 1995), I shed light on five types of masculine values and representations by which brands communicate with changing male consumers.

By connecting brand communication, retailing and masculinity using a semiotic approach, the article offers an original perspective about the production of marketplace discourses on masculinity and the way they address evolving gender roles. It reveals the multiple masculine identities behind these transformations.

The managerial contribution of our article lies in its presentation of the various communication territories available for brands to create captivating masculine narratives depending on their male targets. This will enrich their narratives and question their positioning in the context of a dynamic and changing market (c.f. "The masculinization of the luxury market", Bain and Company, 2012). While brands are tempted to rely on "safe options," using stereotypes of masculinity, the paper offer alternative options for them to rethink their gender representations and connect with emerging masculine representations.

This paper proceeds as follows. First, I provide the conceptual background related to masculinity, consumption and their link to retailing. Next, our methodology section addresses the data collecting process and the semiotic analysis method and is followed by the results section. The final section discusses our findings in the light of previous research, and presents managerial implications.

\section{CONCEPTUAL BACKGROUND}

\subsection{Masculinity and Consumer Research}

Men may now consume products which until recently were denied to them, because they were considered too feminine. Men now use cosmetics (Kimmel and Tissier-Desbordes, 2000; Dano, Roux and Nyeck, 2003; McNeill and Douglas, 2011), fashion, male lingerie (Rinallo, 2007; Ourahmoune, 2009; Ostberg, 2010; Ourahmoune, 2012) and sophisticated decorative items (Otnes and McGrath, 2001)! 
Academic research has started to study the construction and implementation (or performance) of masculinity via consumption. Increasing levels of male consumption can be seen as a potential means of resisting the oppression of gender relationships or other institutional powers, or as a way of establishing agency power against such oppression. The opposing thesis suggests that men consume to escape from the pressure of changing gender relationships (Kimmel, 1994; Belk and Costa, 1998; Schouten and McAlexander, 1995). For Holt and Thompson (2004), the process is more complex; they propose that American masculine ideology is a result of a perpetual negotiation between the Breadwinner model and that of the Rebel, giving rise to the figure of the Man of Action Hero. This negotiation does not take place without tension, and this has resulted in a great deal of interesting recent work (Kimmel and Tissier-Desbordes, 2000; Otnes and Mac Grath, 2001; Elliott and Elliott, 2005; Rinallo, 2007; Ostberg, 2010, Tuncay and Otnes, 2012).

According to Patterson and Elliott (2002), the evolution of masculinity in the market reflects a form of gender equality embodied by "the inversion of the male gaze" in advertising or the representation of the male body as object just as it is widely the case as far as the female body is concerned. The authors consider that this demonstrates the transformation of man as producer into man as consumer and the fact that there is now a range of masculine identities (Schroeder and Zwick, 2004; Holt and Thompson, 2004) or a masculine "polyculture" (e.g. plural culture) (Ourahmoune and Nyeck, 2008). Research into consumer behavior has begun to analyze the strategies men use to interpret these new representations in the market and in advertising in particular (Elliott and Elliott, 2005; Rinallo, 2007).

This work builds on this recent literature to offer an in-depth immersion into luxury retailing to investigate how brands adapt recent socio-cultural and masculine consumer behaviors, as past research has focused only on consumer representations or advertising discourses.

\subsection{Retailing and Masculinity}

Research has investigated how men shop and their differences from women. Otnes and McGrath (2001) discovered three stereotypical models of male shopping behavior: grab and go, whine and wait and fear of the feminine. This last element is crucial with regard to shopping in traditionally feminine settings such as fashion and beauty stores. These authors, along with Mazumdar and Papatla (1995) and Thomas and Garland (2004), claim that men search deliberately, limit price-comparison shopping and browse infrequently. Most of this research takes grocery stores as its field of study, leading to differences from women regarding the speed of shopping, number of items purchased, price per item (Davis and Bell, 1991), frequency of male purchases (Dholakia et al., 1995), objective and subjective criteria (Donegan, 1986; Williams, 2002), and interest in helpful assistants, friendly check out operators and easy parking (Polegato and Zaichowsky, 1994). Male behavior in supermarkets differs from female behavior (Gardner, 2004). Blurring gender norms are now challenging these behavioral differences (Kacen, 2000), as is evidence in the market of greater male interest in shopping and their positive response to product categories such as fashion and skincare, which used to be stigmatized. The retail environment is saturated with signs (Floch, 1995) mediating specific gender norms. The work on ESPN Zone Chicago by Sherry et al. (2004) demonstrates the powerful construction of a hegemonic masculinity through spectacular retailing techniques and the need to understand marketplace gender dialectics through store scenography.

A growing body of research deals with how men interact and construct their identity by consuming traditionally feminine products such as skincare, fashion and lingerie for men (Rinallo, 2007; Otnes and Tuncay-Zayer, 2012; Ourahmoune 2012). However, although researchers have shown great interest in analyzing 'enclaves of masculinity' (La Cecla, 2002) - traditionally masculine territories, such as the Harley Davidson community (Schouten and McAlexander, 1995), the Mountain-Man festivals (Belk and Costa, 1998), and Chicago ESPN Zone (Sherry et al., 2004) - I am not aware of any research dedicated to how traditionally feminine spaces such as fashion stores deal with masculinity to adapt to changing consumer behavior.

This leads me to ask: 'How do luxury brands communicate with changing male consumers in their retail environments?

To address this question, the next section details the methodological procedures applied. 


\section{METHODOLOGY}

\subsection{Rationale for Choosing a Semiotic Approach}

An inductive approach is appropriate to investigate the system of gender representation used by luxury brands in their sales outlets (Dion and Arnould, 2011); it reveals how the retail practices of luxury brands are infused with gender ideologies. Moreover, cultural anthropology and semiotics are particularly useful in consumer research to interpret the deeper meaning of a brand's discourse (Floch, 1995; Mick et al. 1986; Heilbrunn and Hetzel, 2003; Remaury, 2005, Ourahmoune et al, 2014). Finally, a qualitative approach is particularly appropriate when the subject of the study is appearance and aesthetics (Thompson and Hirschman, 1995; Heilbrunn and Hetzel, 2003; Ourahmoune and Ozçaglar-Toulouse, 2012) or gender issues (Holt and Thompson, 2004, Ourahmoune et al., 2014).

This work aims not to study consumer perceptions of in-store stimuli and the sense they make of them, but in-store gender communication strategies. The data used therefore consists of frequent store visits and observation.

\subsection{Criteria for Data Selection}

I selected the 15 brands studied because they lead their particular market (Fashion, Watchmaking and Cosmetics; Eurostaff, 2012). This guaranteed that I studied dominant models and widespread practices in the sector. The 15 stores are located principally in what is known as the "golden triangle" in Paris, and are brand-owned stores. The brands therefore have complete control of how communication is arranged and organized at the point of sale.

The 15 brands included both exclusively masculine brands and brands targeting men and women, to give a wideranging view of gender representations in retail environments. The sample comprised: Vuitton, Gucci, Dior, Boss, Dolce \& Gabbana, and Zegna (fashion); Rolex, Cartier, and Philippe Patek (watch industry); Guerlain, Nickel, Clarins, and Mac (skincare); Hom, and Aubade (lingerie).

\subsection{Data}

The main source of data for this study was observation of the boutiques. After each visit the researcher completed a previously designed analytical grid (design, arrangement, fittings, lighting, colors, style, decoration, product display, representations of men and women on posters in the store, store window, customer pathways, management of customer traffic and floor space organization). I described these different features in a detailed analytical manner after each visit. The brands do not permit in-store photography. Secondly, the researcher kept a journal to note down their observations of interactions between sales assistants and customers and of customer pathways, which enriched the research material appreciably (over 600 pages of field notes).

\subsection{Semiotic Analysis}

The semiotic square is useful to make sense of heterogeneous textual and visual codes; it highlights the hidden meanings behind brand communication (Floch 1995; Heilbrunn and Hetzel, 2003; Dano, Nyeck and Roux; 2003, Holt and Thompson, 2004; Kozinets 2009; Ourahmoune et al 2014). The semiotic square method explains the different (masculine) narratives underlying a (luxury) brand's discourse (Floch, 1995). It is also suitable for “identifying profiles" (Darpy, 1999, p. 4) and masculine archetypes (Dano, Nyeck et Roux, 2003).

I analyzed the brands separately and then compared them to bring out recurring themes and narratives. Applying the semiotic square method for marketing brand analysis by Floch 1995, the author identified correspondences between signifiers and signifieds for each brand and then among brands. Drawing from extensive reading of cultural texts on masculinity and its socio-historical sedimentation in the French context, together with observations and analyses of the retail environments, the author constructed a semiotic square (Floch 1995; Greimas 1986; Holt and Thompson 2004; Ourahmoune and Ozçaglar-Toulouse 2012; Ourahmoune et al., 2014). This method reaches the deepest level of brand discourse, and can establish a structural correspondence between brand expectations and their underlying system. The analysis thus reveals similarities and differences in brand discourses and their corresponding signifiers in the visuals. 
The semiotic square is a useful tool in that it illustrates the complexity of any semantic term (seme). More specifically, Floch (1995) insists that the meaning of each term or concept entails its opposition or contradiction. Our data analysis revealed fundamental oppositions such as the discourse of Reason vs. Emotion, Subject vs. Object etc. However, the semantic opposition that encapsulated the structure of the data most effectively was Utilitarian $v s$. Aesthetic.

'Utilitarian' is only comprehensible in relation to its opposite 'Aesthetic'. However, rather than limiting itself to this binary dimension, the semiotic square suggests another contradictory axis, Non-Utilitarian/ Non-Aesthetic. Thus, it goes beyond binary systems, enhancing understanding of the hidden meanings behind the textual and visual data understood as a single text (Greimas, 1986; Floch, 1995).

Our semiotic square that contrasts two types of discourses, Utilitarian versus Aesthetic reveals five masculine archetypes behind luxury brand in-store communication.

Next I explain each position of the square (each archetype), showing how brand communication through retailing can speak to different masculine values.

Figure 1. Semiotic square: Luxury brands and Masculine archetypes

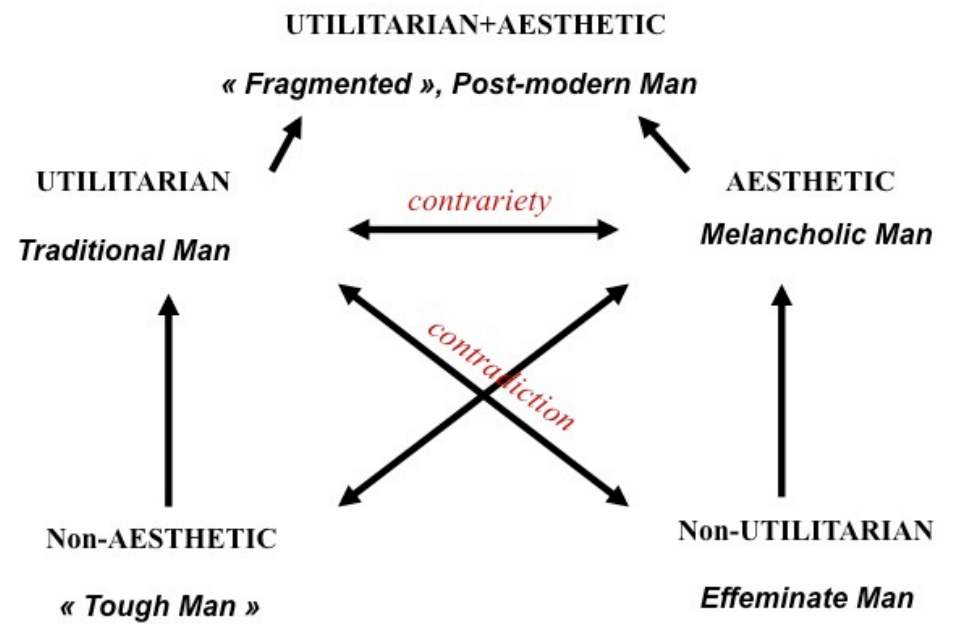

\section{FINDINGS}

I have organized the findings as follows. First, I detail each position of the square as a masculine archetype that emerged from the data, and then I explain how the brands use this archetype in their retail environment.

\subsection{Traditional Man (Utilitarian)}

Utilitarian: refers to what is useful, self-interested; functional, efficient, "producing the desired effect", or to what is "active, powerful and self-determining." (Dictionary Le Petit Robert). It is a traditional masculine characteristic, viewing appearance in pragmatic, practical terms, but also attracted by power and social status, which are instrumental goals. This is Traditional or "Bourgeois" Man.

When you enter the Vuitton store in the Avenue Georges V, the men's department is immediately on the right, just after some display cases with items that might interest men, such as small leather goods. Beyond this a staircase 
leads directly to the first floor, the area dedicated to men, so male customers do not have to go through the rest of the shop, and in particular women's areas. In the men's department, the presentation style contrasts sharply with the rest of the store. Examples of professional or smart casual outfits are displayed prominently, so that men who are not used to shopping and do not want to waste time can choose their clothes quickly. Everything is presented in a short circuit to suggest ideal combinations from jacket to shoes. At the end of the aisle, the circuit finishes with a cozy sitting room furnished with leather armchairs and a selection of books to interest male shoppers. Here the male is back in his world of knowledge and rationality, symbolized by the books. It may also help him to pass the time while his wife continues to explore the temple of leather goods. Vuitton's treatment of its men's department is aimed less at fashion lovers than at men with limited fashion awareness. It seeks to maintain their interest by keeping them separate from other shoppers, by suggesting orthodox combinations, and by allowing them to sustain their rational attitude by reading. Moreover, the books are available for purchase; in the online store they appear in the Men's Collection under "Books and Writing" a section which, until recently, did not exist in the Women's collection.

In the Zegna store, we find the Bourgeois man, sober and serious. Here, the strategy is to display piles of clothes in a restrained, wood-lined atmosphere. To avoid wasting time, a sales assistant immediately takes charge of the customer. His language is precise and technical: shopping appears less of a leisure activity than a serious task that reinforces the male's social standing. The brand is looking to give the services of an old-fashioned tailor, with no sign of frivolousness. The strategy of stacking the clothes and displaying images of men in traditional suits everywhere in the store is based on the idea that sobriety is essential for a man. Rolex, in a different register, favors symbols of power in its sales outlet: the simple style, with solid wood and precious metals, shows the high social status enjoyed by the store's customers. All the representations show an active man, expressing himself in public, at the microphone or in front of an audience, admired by his peers. It is as if this is the reward for shopping here. The products are displayed in large quantities, as a sign of opulence; they are lined up geometrically, in price order, in a hierarchy that seems to reflect social stratification.

\subsection{Melancholic Man (Aesthetic)}

Aesthetic: Etymologically, this word refers to collective emotion, and to "the science of beauty." It is linked to the Art World: disinterested, altruistic, admirable and emotional. It is characteristic of the melancholic man, who is interested in art, poetry and literature. He is attentive to emotions, feelings and beauty (cf. the Dandy); he adopts the passive position of the object in interpersonal relations. This is the Melancholic Man.

Luxury-brand advertising for men has frequently used this archetype in recent years. Brands such as Gucci, Vuitton, Prada, Dior and Saint-Laurent Paris, for example, display copious images of this man: emotional, refined in a way reminiscent of the dandy, subtle, thoughtful, a dreamer. Unlike traditional representations linked to power and professional life, here the accent is on existential values. Yet this archetype is rarely present in representations at the point of sale, where the atmosphere is much more conservative, highlighting traditional, utilitarian male values. Gucci, however, is an exception to this rule. Its store concept values aestheticism in the extreme, style is the dominant impression given in both its men's and women's departments. Attention to detail, to the beautiful and to emotion is manifest in the organization of its sales area, independently of gender distinctions. Lighting effects, intersections between different areas and product displays all follow a coherent design based on emotional rather than utilitarian values. The lavishness and sophistication contrast sharply with more traditional men's departments; its spectacular nature is very different from the sobriety and efficiency other brands display in their stores. As Barbey d'Aurevilly wrote "Appearance is for dandies as well as for women." We can see in the store's design and layout the perfect attentions of a bourgeois woman planning her house from top to bottom. The store design concept employs open space, warm luxurious materials and natural light to spectacular effect, is a departure from traditional codified fashion retail spaces, and paves the way for Gucci's contemporary look. Signature Gucci materials of rosewood and marble are enhanced with the introduction of new elements such as ribbed glass, warm polished gold, smoked mirrors and bronze glass, recalling the elegance and richness of the Art Deco era. Walls covered in both bronze glass and bronze mirrors contribute to the warm intimacy and sophistication of the store environment. Here gender is not a concern; both masculinity and femininity are observed from a romantic, aesthetic perspective which, for men, recalls the age of the dandy. 


\section{3. "Tough Guy" (Non-Aesthetic)}

Non-Aesthetic: Refers to "the tough guy" who rejects any sign of femininity, and hence any preoccupation with beauty, body ornamentation or artifice, considered to be feminine and a threat to virility (cf. La Cecla, 2002, on Sicilian males). This strongly assertive attitude attempts to dominate interpersonal relations. This is the Tough Guy.

The world of the cosmetics brand Nickel is absolutely unambiguous: there is no room for femininity here. According to the brand's managers, it is dedicated to 'cleaning' men's skin rather than making it attractive. When the brand was launched in the middle of the nineties, its stated aim, as suggested by the name (which in colloquial French means "sparkling clean"), was to target masculine cleanliness with "100\% masculine" skincare products. The brand soon began to emphasize its expertise in men's skincare: more often damaged and less delicate. Conveying a message based on male virility, the brand's care products and beauty services, with evocative names such as "Sports Massage," "Love Handle Wrap" and "Morning After Rescue," have given the brand a great deal of success, attracting both consumers who often use care products and neophytes who are reassured by the brand's very direct "masculine" messages. In the Paris store, the products, soberly packaged, are lined up in a way reminiscent of DIY stores. The store is fitted out using cold materials and clean lines, and the only representations present are masculine, with muscular, active bodies using the products in a way that is totally lacking in mannerisms or feminine gestures. The stores convey a "men only" atmosphere, positioning the brand as the authentic masculine brand, unlike the market leaders that have recently developed their range to target the growing male sector.

\subsection{Effeminate Man (Non-Utilitarian)}

Non-Utilitarian: This refers to the effeminate man who adopts feminine aesthetic codes and rejects the traditional masculine appearance based on functionality and virility. His idea of seduction is based on "having" rather than "being", and he values feminine gestures and mannerisms that make him an "ultraobject." This is the Effeminate Man.

None of the brands analyzed during this study adopt this position. I selected the market leaders, and they doubtless consider that such a radical position towards gender codes would be too risky. However, brands such as Jean-Paul Gaultier do express explicitly feminine codes, since they promote the transfer of products and gestures from feminine culture to men, using images, for example, of an extremely slim model, whose masculinity is hardly distinguishable, applying mascara in front of his mirror. The flagship store in the Avenue George $\mathrm{V}$, designed in collaboration with Philippe Starck, radiates femininity. Its skin colored recesses and rounded shapes give it a delicate, precious atmosphere. The filtered lighting in the male area shows off some of the brand's iconic creations such as the skirt for men.

\subsection{The Postmodern Man (Utilitarian+Aesthetic)}

Utilitarian + Aesthetic: This is the androgynous "fragmented", postmodern man, who combines aesthetic and utilitarian values. Depending on the context and his mood, he will affirm traditionally feminine behavior linked to appearance, seduction and emotions, whilst at the same time favoring functionality, performance, social status and professional success. Even when he is involved in social and public life, he is concerned by certain traditionally feminine aspects of private life; he can be in turn object and subject. This is the Fragmented/Postmodern Man.

This is the position that brands covet most today: that of a man who acknowledges his feminine side, or enough complexity to enable him to flirt with feminine consumption, whilst at the same time maintaining his appetite for efficiency, social success and virility.

In the watchmaking sector, Patek Philippe fits the postmodern register perfectly. In an overwhelmingly masculine universe - the watch is, of course, the perfect example of masculine jewelry - the brand communicates using the traditional codes of the watchmaker's skills and the notion of inter-generational transmission. Its store, at 10, place Vendôme in Paris, is laid out in a way that is familiar to its international clientele, with its love of watch movements 
and aesthetics. The art deco styled store is warm, welcoming, convivial and refined. However, from the gender perspective, the brand is sometimes unorthodox. When it recently renovated the store, it launched a woman's chronograph, to the surprise of the market. At the same time, its shop windows and interior were decorated to represent Nature in a surreal way, at once lively and dreamlike. This poetic "hyper-real" style, blended with classicism, creates an environment where opposites merge and our relationship to time is both utilitarian and existential, suggesting the fragmentation of the modern world.

HOM, the men's underwear brand, which in France promotes "men's lingerie," can represent the same man as a high-level athlete, a father relating to and playing with his children, and a seducer, wearing fine underwear and acting as a man-object for the evening. For these different uses, the brand creates specific display cases alternating traditional underwear and "lingerie," intentionally representing a man with a firm, athletic, unambiguously virile body, but with a fragmented life. The brand announces "Underwear for every occasion," and, like Patek Philippe, represents different scenes from life and the fact of living several lives in one, a very postmodern leitmotiv (Maffesoli, 1990); it asks the consumer "Who will you be in the next 24 hours?"

\section{DISCUSSION OF THEORETICAL AND MANAGERIAL CONTRIBUTIONS}

In recent years, luxury brands have increasingly shown interest in the growing, male consumer market. Recent literature in the field of customer behavior suggests that there is a movement away from masculinity to types of masculinity, with the possibility in western societies of being a man in many different ways (Holt and Thompson, 2004; Schroeder and Zwick, 2004; Ourahmoune and Nyeck, 2008). Luxury brands in particular have contributed to the change in male representations from producers to consumers (Schroeder and Zwick, 2004). Most conceptualizations in this field study advertising. I argue in this paper that research should also investigate representations of masculinity in retail environments, which are important channels for brand communication. I propose five masculine archetypes through which brands express masculine narratives, to address current research dealing with branding and changing gender norms.

The article makes several contributions to the field. Firstly, although the dynamism of sales to men in the luxury sector leads companies to pay particular attention to sales areas dedicated to men, many brands maintain conservative representations of masculinity (suggesting that shopping is a more feminine activity, and that seriousness and efficiency are the overriding masculine values). In this way luxury brands ignore several areas of communication to men where they might show themselves to be distinctive. This adds to the growing literature in masculine consumer behavior analysing the tension experienced by men steering a path through the fashion market but suffering from social anxiety (Kimmel and Tissier-Desbordes, 2000; Rinallo 2007; Otnes and Tuncay-Zayer, 2012). My findings suggest that these tensions are amplified by retailing strategies that reinforce the stereotype of the traditional, utilitarian man, missing opportunities to connect with male consumers interested in more pleasant, entertaining or aesthetic shopping. It is possible to help men cope with the social tensions that prompt them to ignore their emotional side by developing more complex in-store narratives, communicating via the various meanings of masculinity. New male segments that disrupt the tradition of shopping by obligation, for instrumental reasons rather than for pleasure, might perceive such a strategy positively. Given that emerging markets are becoming critical for the success of luxury brands in Paris (50\% of sales made to Chinese tourists), it is necessary for brands take account of the fact that these consumers are much younger than Western tourists (Bain and Company, 2011) and are eager to experiment with different masculine values. It is risky then for brands to maintain a single discourse based on traditional utilitarian values only.

The second contribution concerns the hypothesis of "the inversion of the male gaze" (Patterson and Elliott, 2002), which concludes that in advertising the male body has been reified in the same way as the female. My study demonstrates that in the retail environment this is not always the case.

With rare exceptions, even those brands that use emotional representations of men in their advertising continue to convey traditional views of masculinity in their retail environments. Our research supports Schroder and Zwick's (2004) study, which concludes that the male gaze has expanded rather than reversed within advertising. This research detects five specific archetypes but acknowledges the supremacy of traditional narratives. Nonetheless, this result invites researchers to measure the effect of the display of different masculine representations in different 
communication channels. For instance, Christian Dior displays Melancholic men in its advertising but traditional men in its stores. This could explain the paradox between the high regard men have for this brand and its poor sales in the masculine segment.

Third, in response to the appeal to investigate marketplace productions of masculinity (Otnes and Zayer, 2013) this research identifies five archetypes of masculinity in the French context (Bourgeois, Melancholic, Fragmented, Tough and Effeminate Man). Each archetype has its own discourse register that speaks to specific masculine values embodied by in-store storytelling. The model proposed using the semiotic square could also explain gender strategies in other brands' communication. Previous research has proposed three types of masculinity based on consumer discourses in the American context: the Breadwinner, the Rebel, and the Man-of-action hero (Holt and Thompson, 2004). The differences between the two typologies reveal how masculine ideologies are connected to the cultural context and social history. The transfer of power from the aristocracy to the bourgeoisie in France totally redefined the norms for male fashion and luxury consumption. Meanwhile in America, colonization and the Pilgrim Fathers gave a heroic perspective to the meta-narrative of American masculinity. If brands dig deeper into the connections between macro-social structures and masculine ideology in various contexts, they will better frame and enrich their stories. My research extends this field and offers a way to map the different views of masculinity and help understand how dominant masculine ideologies co-exist with minor ones that have already inspired market leaders. In a context of rapidly changing markets, brands that stand apart from habitual discourses can target a growing, complex segment of younger male luxury consumers from emerging markets (Bain and Company, 2011).

The fourth contribution of this research is to reveal that when brands target both men and women, they can convey a rarely used egalitarian ideology, like the brand BOSS. Other brands display the same unifying style for both men and women at the point of sale (Gucci) but, rather than promote gender equality, display a lack of concern for the issue. This last situation possibly deprives the brand of an added dimension to its discourse at the POS, concerning a very formative aspect of identity. Most brands align with traditional discourse, such as instrumental and emotional values for men women respectively (Vuitton). This is because gender is insufficiently questioned in retailing environments, although it could be leveraged to create captivating stories for consumers. Research has not tackled how brands should manage the gendered aspects of their stores when dealing both with men and woman. This research gives a first glimpse into how gendered narratives in a context of changing sociocultural norms can build up messages in retail environments that are as varied, refined and desirable as those prevailing in advertising.

\section{CONCLUSION}

As stated by Holt (1997), the postmodern era makes it difficult for marketers to achieve an efficient branding strategy without digging into the subtle differences between diverse collectivities. The many ways in which men can express their masculine identity pose significant challenges for marketers hoping to create captivating stories in an increasingly masculine luxury market. Retail storytelling can enhance the study of market productions of masculinity by adding to the knowledge gained by analyzing masculinity in advertising. My semiotic analysis, mapping the various types of masculinity represented by brands, adds to the growing body of research that tackles masculinity from a managerial perspective rather than the usual consumer-driven perspective. It sheds light on the various territories that brands can leverage to connect with changing male consumers. Yet the results also show a lack of action in stores; brands rely on traditional bourgeois discourses that stress utilitarian values, even when they have shifted to emotional narratives in their advertising.

Finally, the article is based on a study conducted in Paris. This is certainly an iconic city for the luxury market, but it is vital for researchers to investigate other cultural contexts to account for the changing sociocultural norms affecting male-related business areas.

\section{AUTHOR BIOGRAPHY}

Nacima Ourahmoune is Associate Professor of Marketing and Consumer Culture at Kedge Business School, France. Her research analyzes how social transformations influence marketing and consumption phenomena. Nacima has presented her work at over 40 leading international conferences, and published in Journal of Applied Business Research, Journal of Business Research, Marketing Theory, Journal of Macromarketing, Journal of 
Consumer Behavior, Développement Durable et Territoires, Revue de l'Organisation Resonsable, Advances in Consumer Research, and contributed to several books. Email: nacima.ourahmoune@kedgebs.com

\section{REFERENCES}

Arnould, E.J., Thompson, C.J., 2005. Consumer culture theory (CCT): Twenty years of research. Journal of Consumer Research $31(4), 868-882$.

Bain and Company, 2012. Luxury Goods Worldwide Market study.

Baudrillard, 1979 De La Séduction, Seuil, Paris.

Belk, R.W., Costa, J.A., 1998. The mountain man myth: A contemporary consuming fantasy. Journal of Consumer Research 25 , 218-240.

Davis, G., Bell, J., 1991. The grocery shopper-is he different? International Journal of Retail and Distribution Management 19 (1), 25-28.

Dholakia, R.R., 1999. Going shopping: key determinants of shopping behaviours and motivations. International Journal of Retail and Distribution Management 27 (4), 154-165.

Dion, D., Arnould, E., 2011. Retail luxury strategy: Assembling charisma through art and magic. Journal of Retailing 87 (4), $502-520$.

Donegan, P.,1986. The myth of the male shopper. Progressive Grocer May, 36-42.

Elliott, R., Elliott, C., 2005. Idealised images of the male body in advertising: A reader-response exploration. Journal of Marketing Communications 11 (1), 3-20.

Eurostaf, 2008. Le Marché Mondial du Luxe.

Floch, J.M., 1995. Identités Visuelles, PUF, Paris.

Gardner, M., 2004. What men want-in the supermarket. The Christian Science Monitor 23 (1), 11-15.

Heilbrunn, B., Hetzel, P., 2003. La pensée bricoleuse ou le bonheur des signes : ce que le marketing doit à Jean-Marie Floch. Décisions Marketing 29, 19-23.

Holt, D.B., Thompson, C.J., 2004. Man-of-action heroes: The pursuit of heroic masculinity in everyday consumption. Journal of Consumer Research 3, 425-440.

Kacen, J., 2000. (2000) "Girrrl power and boyyy nature: the past, present, and paradisal future of consumer gender identity", Marketing Intelligence \& Planning, Vol. 18 Iss: 6/7, pp.345 - 355

Kimmel, A.J., Tissier-Desbordes, E., 2000. Males, masculinity, and consumption: An exploratory investigation, in: Dubois, B., Lowrey, T.M., Shrum, L.J., Vanhuele, M. (Eds.), European Advances in Consumer Research, Association for Consumer Research, Provo, UT, pp. 243-251.

Kozinets, R.V., 2009. Technology/ideology: How ideological fields influence consumers' technology narratives. Journal of Consumer Research 34 (6), 864-881.

La Cecla, F., 2002. Ce qui fait un homme, Seuil Diffusion, Paris..

Maffesoli, M., 1990. Au Creux des Apparences, Pour une Ethique de 1'Esthétique, Plon, Paris.

Mazumdar, T., Papatla, P., 1995. Effects of shopping basket size on price and promotion responses. Pricing Strategy and Practice $3(3), 16-24$.

McNeill, L. S., Douglas, K., 2011. Retailing Masculinity: Gender expectations and social image of male grooming products in New Zealand. Journal of Retailing and Consumer Services, 18 (5), 448-454.

Mick, D.G., 1986. Consumer research and semiotics: Exploring the morphology of signs, symbols and significance. Journal of Consumer Research 13 (2), 196-213.

Miller, D., 1987. Material Culture and Mass Consumption, Blackwell Publishers, London.

Ostberg, J., 2010. Thou shalt sport a banana in thy pocket: Gendered body size ideals in advertising and popular culture. Marketing Theory 10 (1), 45-73.

Otnes, C.C., McGrath, M.A., 2001. Perceptions and realities of male shopping behavior. Journal of Retailing 77 (1), $111-137$.

Otnes, C.C., Tuncay-Zayer, L., 2012. Gender, Culture and Consumer Behavior, Routledge, New York.

Ourahmoune, N., 2012. Masculinity, intimacy and consumption, in: Otnes, C., Tuncay-Zayer, L. (Eds.), Gender, Culture and Consumer Behavior. Routledge, New York, pp. 311-331.

Ourahmoune, N., Özçağlar-Toulouse, N., 2012. Exogamous weddings and fashion in a rising consumer culture: Kabyle minority dynamics of structure and agency. Marketing Theory 12 (1), 81-99.

Ourahmoune N., Binninger A-S., Robert I., 2014. Brand Narratives, Sustainability, and Gender: A Socio-semiotic Approach. Journal of Macromarketing first published on April 23, 2014.

Ourahmoune, N., Nyeck, S. 2008. Gender Values and Brand Communication: The transfer of Masculine representations to brand narratives. European Advances in Consumer Research 8, 181-188.

Patterson, M., Elliott, R., 2002. Negotiating masculinities: Advertising and the inversion of the male gaze. Consumption, Markets and Culture 5 (3), 231-246.

Polegato, R., Zaichkowsky, J.L., 1994. Family food shopping: strategies used by husbands and wives. Journal of Consumer Affairs 28 (2), 278-300. 
Remaury, B., 2005. L'objet de luxe à l'ère de la reproductibilité technique, in: Assouly, O. (Ed.), Le Luxe - Essais sur la Fabrique de l'Ostentation. Editions de l'Institut Français de la Mode, Paris, pp. 371-385

Rinallo, D., 2007. Metro/fashion/tribes of men: Negotiating the boundaries of men's legitimate consumption, in: Cova, B., Kozinets, R.V., Shankar, A. (Eds.), Consumer Tribes. Elsevier/Butterworth-Heinemann, Oxford, UK, pp. 76-92.

Schouten, J.W., McAlexander, J.H., 1995. Subcultures of consumption: An ethnography of the new bikers. Journal of Consumer Research 22, 43-61.

Schroeder, J.E., Zwick, D., 2004. Mirrors of masculinity: Representation and identity in advertising images. Consumption, Markets and Culture 7 (1), 21-52.

Sherry Jr, J.F., Kozinets, R.V., Duhachek, A., DeBerry-Spence, B., Nuttavuthisit, K., Storm, D., 2004. Gendered behavior in a male preserve: Role-playing at ESPN zone Chicago. Journal of Consumer Psychology 14 (1/2), 151-158.

Thomas, A., Garland, R., 2004. Grocery shopping: list and non-list usage. Marketing Intelligence \& Planning, 22 (6), 623 - 635

Thompson, C.J., Hirschman, E.C., 1995. Understanding the socialized body: a poststructuralist analysis of consumers' selfconceptions, body-images, and self-care practices. Journal of Consumer Research 22,139-153.

Thompson, J. C., Haytko, D., 1997. Speaking of Fashion: Consumers' Uses of Fashion Discourses and the Appropriation of Countervailing Cultural Meanings. Journal of Consumer Research 24 (1), 15-42.

Tuncay, L., Otnes, C., 2008. The use of persuasion management strategies by identity-vulnerable consumers: The case of heterosexual male shoppers. Journal of Retailing 84, 487-499.

Vigarello, G., 2004. Histoire de la Beauté. Le Corps et l'Art d'Embellir, de la Renaissance à Nos Jours, Seuil, Paris.

Welzer-Lang, D., 2004. Les hommes aussi changent, Payot, Paris.

Williams, T.G., 2002. Social class influence on purchase evaluation criteria. The Journal of Consumer Marketing 19 (3), $249-$ 277. 


\section{NOTES}

